\title{
Prevalência de hemoglobinas variantes em comunidades quilombolas no estado do Piauí, Brasil
}

\author{
Prevalence of hemoglobin variants \\ in quilombola communities in the state of Piauí, Brazil
}

\author{
Leonardo Ferreira Soares ${ }^{1}$ \\ Eleonidas Moura Lima ${ }^{1}$ \\ José Alexsandro da Silva ${ }^{1}$ \\ Suenia Soares Fernandes ${ }^{1}$ \\ Keyla Malba da Costa Silva ${ }^{1}$ \\ Sarah Pereira Lins ${ }^{1}$ \\ Bolivar Ponciano Goulart de Lima Damasceno ${ }^{1}$ \\ Roseane Mara Cardoso Lima Verde ${ }^{2}$ \\ Marilda de Souza Gonçalves ${ }^{3}$
}

${ }^{1}$ Departamento de Bioquímica e Farmacologia, Centro de Ciências da Saúde, Universidade Estadual da Paraíba. Campus Universitário da Ininga, Ininga. 64049550 Teresina PI Brasil. leonardosoares@ hotmail.com

${ }^{2}$ Universidade do Vale do Paraíba. São José dos Campos SP Brasil. ${ }^{3}$ Faculdade de Medicina, Universidade Federal da Bahia. Salvador BA Brasil.

\begin{abstract}
Hemoglobin variants $(\mathrm{Hb})$ result from mutations in globin genes, with amino acid substitution in the polypeptide chain. Among the most common structural variants are $\mathrm{HbS}, \mathrm{HbC}, \mathrm{HbD}$ and $\mathrm{HbE}$. The $S$ hemoglobin gene is a high frequency gene across America and Brazil, where it is more frequent in the Southeast and Northeast. The scope of this article is to investigate the presence of hemoglobin variants in 15 quilombos (fugitive slave communities) of Piaui. The sample was of 1,239 people and hemoglobin was screened by high-performance liquid chromatography (HPLC). A questionnaire was applied related to gender, ethnicity and consanguinity. Of the samples analyzed, 5.4\% had AS sickle cell trait, while SS and SC sickle cell anemia showed a rate of $0.8 \%$, with $A C, A D$ and DD hemoglobin. Of the 1,069 Afro-descendants, 84 revealed hemoglobin abnormalities, 34 being male 53 being female. There were 13 consanguineous marriages among the 84 hemoglobin alterations. The study of hemoglobin variants in 15 former quilombo communities in the state of Piaui contributes to their education in health in the aspects of genetic inheritance of hemoglobin, a relevant public health issue, providing input for the implementation of the State Program of Sickle Cell Disease of Piaui.

Key words Sickle cell disease, Sickle cell trait, Health of the Afro-descendant population
\end{abstract}

Resumo As hemoglobinas variantes $(\mathrm{Hb})$ decorrem de mutações nos genes da globina. As variantes estruturais mais frequentes são $H b S$, $\mathrm{HbC}, \mathrm{HbD}$ e HbE. O gene da hemoglobina S tem frequência elevada na América, enquanto que no Brasil é maior no Sudeste e Nordeste. O presente artigo tem por objetivo investigar a presença de hemoglobinas variantes em 15 comunidades quilombolas do estado do Piauí. Foram analisadas 1.239 amostras, nas quais as hemoglobinas foram triadas pela cromatografia líquida de alta eficiência (HPLC). Aplicou-se questionário referente a gênero, etnia e consanguinidade das populações. Das 1.239 amostras, 5,4\% apresentaram o traço falciforme AS, as doenças falciformes SS e SC apareceram em $0,8 \%$ do total, nas hemoglobinas $A C$, $A D$ e DD. Das 1.069 pessoas negras, 84 apresentaram alteração das hemoglobinas; destas, 34 eram do sexo masculino e 53 do feminino. Ocorreu a presença de 13 casamentos consanguíneos dentre as 84 alterações das hemoglobinas. O estudo das hemoglobinas variantes em 15 comunidades remanescentes de quilombos do Piauí contribui para sua educação em saúde frente aos aspectos da herança genética destas proteinas, relevante questão de saúde pública, proporcionando subsídios para a implantação do Programa Estadual da Doença Falciforme do Piauí.

Palavras-chave Doença falciforme, Traço falciforme, Saúde da população negra 


\section{Introdução}

A Doença Falciforme (DF) originou-se na África, estendeu-se para a Península Arábica, sul da Itália, Índia e foi trazida às Américas pela imigração forçada de cerca de 3-4 milhões de africanos vindos como escravos. Considerada a patologia genética de maior prevalência mundial, a anemia falciforme possui uma frequência de 25 a $40 \%$ em países africanos. A população brasileira apresenta uma composição de mistura de três grupos genéticos, ameríndios, europeus e africanos, sendo estes últimos um conjunto de diversos grupos étnicos. Este grupo veio para o Brasil na condição de escravos, sendo que em várias regiões do país formaram quilombos, comunidades de fugidos. No campo da saúde pública a ênfase na anemia falciforme como doença étnico-racial apoia-se em três aspectos relacionados a essa patologia que caracterizariam uma maior suscetibilidade da população negra e parda: origem geográfica, etiologia genética e estatísticas de prevalência ${ }^{1-5}$.

O gene da hemoglobina $S$ é de alta frequência em toda a América e no Brasil, país este no qual é mais frequente nas regiões sudeste e nordeste. $\mathrm{Na}$ África Equatorial $40 \%$ da população é portadora e a doença falciforme atinge uma prevalência de 2 a $3 \%$ da população. No Brasil, a anemia falciforme acomete de 0,1 a $0,3 \%$ da população negra, com tendência a atingir parcela cada vez mais significativa da população, devido ao alto grau de miscigenação em nosso país. De fato, estudos populacionais têm demonstrado a crescente presença de hemoglobina $\mathrm{S}$ em indivíduos caucasoides ${ }^{3}$.

A DF engloba um conjunto de alterações genéticas diferentes, que permeia desde formas leves, muitas vezes assintomáticas, até formas graves com alta taxa de mortalidade. A Hemoglobina $\mathrm{S}$ (Hb S) é uma mutação no gene da globina, devido à troca de uma base nitrogenada na posição 6. Assim, o ácido glutâmico (GAG) é substituído pela valina (GTG), resultando na expressão do gene ${ }^{\text {s, }}$ com modificação estrutural de sua função. A hemoglobina $\mathrm{C}(\mathrm{Hb} \mathrm{C})$ é oriunda da troca do ácido glutâmico pela lisina (AAG). Indivíduos que apresentam a HbS em homozigose (SS) evidenciam uma condição grave da doença, enquanto que aqueles com a HbS em heterozigose AS não apresentam manifestações clínicas, exceto em circunstâncias excepcionais, conferindo uma vida normal ao seu portador. No Brasil, distribui-se heterogeneamente, apresentando índice médio de $0,3 \%$ da população com elevada prevalência de antepassados negros, destacando- se principalmente os estados da Bahia, Maranhão e Piauí. A prevalência do traço falciforme é maior nas regiões Norte e Nordeste, entre $6 \%$ e $10 \%$, enquanto que nas sul e sudeste é de $2 \%$ a $3 \%$, heterozigotos AC alternam de 1 a 3\%, $\%^{3,6-10}$.

O termo DF é utilizado para definir as formas clínicas associadas à presença da $\mathrm{HbS}$, seja em homozigose ou em associação com outras hemoglobinas variantes ou talassemias; como, por exemplo, a doença SC e a talassemia beta $\mathrm{S}$, respectivamente.

A doença falciforme é originária do continente africano, tendo se estendido para a Península Arábica, sul da Itália e Îndia e sendo depois trazida às Américas por cerca de 3-4 milhões de escravos africanos ${ }^{2,6,11}$.

$\mathrm{Na}$ anemia falciforme ocorre uma polimerização da hemoglobina $S$ na ausência de oxigênio, promovendo alterações na estrutura das hemácias, que tomam a forma de foice ou "sickle" na língua inglesa. As doenças falciformes são genéticas, crônicas e sem cura ${ }^{7}$.

As DF decorrem da mutação no gene da hemoglobina, na qual as situações que provocam baixa tensão de oxigênio sanguíneo (desidratação, esforço físico intenso, altas e baixas temperaturas, estresse) provocam a falcização da hemácia. Esta, em foice, causa vaso-oclusão na microcirculação, acarretando em isquemia e necrose tecidual, o que desencadeia crises álgicas e complicações, principais responsáveis pelas interferências na vida daqueles com esta doenç ${ }^{12}$.

Não existem dados epidemiológicos relativos à Doença Falciforme nestas comunidades, o que torna a presente pesquisa em um marco teórico desta enfermidade no Piauí, trazendo consigo a afirmação do direito à saúde e um resgate histórico desta população.

\section{Populações quilombolas}

O Programa das Nações Unidas para o Desenvolvimento (PNUD) afirma que as Comunidades Negras Rurais remanescentes de quilombos, denominadas quilombolas, são hoje um dos mais ativos agentes sociais da população negra no Brasil, os quais, unidos pela força da identidade étnica, travam no dia-a-dia um embate pelo direito à terra, à educação e à saúde ${ }^{13}$.

Quilombo denomina o local onde os escravizados, revoltados, organizavam-se para fugir das senzalas e das plantações, ocupando as partes dos territórios brasileiros não povoados e, geralmente, de acesso difícil. Palavra originária dos povos de língua Bantu (Kilombo), sua presença e seu 
significado no Brasil têm a ver com alguns desses povos, cujos membros foram trazidos como escravos para esta terra ${ }^{14}$.

A figura "remanescente de quilombo" significa uma nova dimensão para além da concepção arqueológica inaugurada desde a promulgação da Constituição da República Federativa do Brasil de 1988, que reconhece, no artigo 68, a posse definitiva da terra e a obrigatoriedade do Estado na emissão dos títulos correspondentes a toda comunidade remanescente e nos direitos constitucionais à saúde e educação ${ }^{15}$.

A visibilidade atual dos grupos quilombolas deve-se ao processo de reconhecimento de seus direitos territoriais. $\mathrm{O}$ enfoque desses novos estudos segue a lógica das diferenças culturais. Por sua vez, as comunidades quilombolas são reconhecidas como grupos étnicos, agora diferentes das comunidades negras rurais ${ }^{16}$.

A maioria das dificuldades relacionadas à saúde desta população não são resultantes de suas características genéticas (pelo fato de serem negros ou descendentes de africanos). São resultantes de suas condições socioeconômicas e educacionais e das desigualdades históricas também relacionadas com a pobreza ${ }^{17}$.

A temática do acesso à saúde nas comunidades quilombolas ainda é um grave problema, principalmente quando analisamos as responsabilidades público-privadas quando às questões da exclusão-inclusão, desigualdade-igualdade, iniquidade-equidade, do gerenciamento do sistema sanitário e do respeito à cultura e identidade étnica ${ }^{18}$.

Dados da Coordenação Nacional de Articulação das Comunidades Negras Rurais Quilombolas (CONAQ) constatam a presença de mais de 3 mil comunidades no Brasil. Segundo levantamentos realizados pela Coordenação Estadual das Comunidades Negras Rurais Quilombolas, existem no estado do Piauí, região Nordeste do Brasil, (125) cento e vinte e cinco comunidades já identificadas na zona rural ${ }^{19}$.

O objetivo do presente estudo foi apresentar a prevalência da doença e do traço falciforme em 15 comunidades quilombolas no estado do Piauí.

\section{Método}

Estudo transversal realizada no período de julho a outubro de 2010, tendo como população alvo 1.239 habitantes de 15 comunidades Quilombolas localizado no estado do Piauí. A amostragem foi do tipo não probabilístico, voluntária.
Após discussão em várias reuniões com as lideranças da coordenação estadual das comunidades quilombolas do estado do Piauí e as lideranças locais, a proposta de pesquisa foi aceita e submetida ao conselho Nacional de Ética em Pesquisa (CONEP) e aprovado pelo Conselho de Ética em Pesquisa da Universidade Federal do Piauí (UFPI).

Participaram 1.239 membros das comunidades: Tapuio, Sumidouro, Volta do Riacho, São Martins, Cana Brava, Custaneira, Angical de baixo, Contente, Grotões, Carreiras, Mutamba, Atrás da Serra, Lagoa Grande, Mimbó e Caldeirão

Foram considerados critérios de inclusão para a pesquisa ser membro das comunidades quilombolas em estudo, sem limites de idade. Após assinatura de termo de consentimento livre e esclarecido da pesquisa, os membros foram convidados a participar da sensibilização sobre o que é a doença e o traço falciforme, assim como esclarecimentos acerca dos exames a serem realizados, em seguida ocorreu a coleta de amostras para o diagnóstico, quando foram coletados $5 \mathrm{ml}$ de sangue em tubos contendo o ácido etileno diamino tetracético (EDTA). Foram aplicados aos sujeitos da pesquisa questionário semiestruturado referente a gênero, etnia e consanguinidade entre as populações em estudo.

\section{Localização e perfil das comunidades quilombolas estudadas}

As comunidades quilombolas Tapuio (128 habitantes), Sumidouro (140 habitantes) e Volta do Riacho (120 habitantes), estão localizadas no município de Queimada Nova, cidade que faz fronteira com o estado de Pernambuco, apresentando população total de 8.332 habitantes. As comunidades Angical de Baixo (144 habitantes), Contente (188 habitantes) e São Martins (164 habitantes) localizam-se no município de Paulistana, o qual apresenta uma população de 16.529 habitantes. As comunidades Atrás da Serra $(89$ habitantes), Cana Brava (150 habitantes), Carreiras (160 habitantes), Custaneira (200 habitantes), Grotões (90 habitantes), Lagoa Grande (70 habitantes) e Mutamba (80 habitantes) localizam-se no município de Santa Cruz do Piauí, com uma população total de 5.682 habitantes. As comunidades Caldeirão (80 habitantes) e Mimbó (520 habitantes) localizam-se no município de Amarante, cidade fronteiriça com o estado do Maranhão, o qual apresenta uma população de 16.884 habitantes, segundo o IBGE em $2000^{20}$.

Todas as comunidades distam a $10 \mathrm{~km}$, em 
média, dos perímetros urbanos, com acesso por estradas de terra. O Território vale do Rio Guaribas, onde localizam-se as cidades, é constituído por pequenos municípios nos quais 29 (81\%) possuem população de até 10.000 habitantes revelando-se essencialmente rural. Os Indicadores de Desenvolvimento Humano (IDH) desta região situam-na entre os piores índices do estado do Piauí, sendo a renda o fator de maior influência negativa na média geral ${ }^{21}$.

Levantamentos realizados pela Coordenação Estadual das Comunidades Negras Rurais Quilombolas do estado do Piauí evidenciam que essas comunidades vivem a partir do uso comum da terra, requerendo um olhar especial nas atividades realizadas. A escassa atividade agrícola é a fonte de sustento da maioria das famílias, porém, a complementação econômica das famílias advém de projetos do governo Federal, como a Bolsa Família e as cestas básicas da Companhia Nacional de Abastecimento (CONAB) ${ }^{16}$.

As sensibilizações sobre as raízes étnicas relacionadas à doença falciforme, além da coleta do material biológico para a realização dos exames, foram realizadas nos locais utilizados para reuniões e decisões das comunidades.

Uma vez coletadas, as amostras eram adequadamente conservadas em caixas térmicas refrigeradas a $4^{\circ} \mathrm{C}$ até a sua manipulação no Laboratório de Hematologia do curso de Farmácia da Universidade Federal do Piauí. Os resultados dos exames e os questionários foram tabulados utilizando o programa STATA $10^{22}$.

\section{Pesquisa de hemoglobinas variantes}

As amostras foram triadas para hemoglobinas variantes pelo método da cromatografia líquida de alta performance (HPLC), aparelho composto por um sistema Analisador de Hemoglobinas, VARIANT-II (Bio-Rad, CA, USA), utilizando o kit Beta thal. O HPLC possui maior acurácia do que os procedimentos eletroforéticos. O sistema automatizado é de fácil manuseio e os resultados são apresentados rapidamente ${ }^{23}$.

\section{Resultados e discussão}

A Tabela 1 apresenta a frequência geral de hemoglobinas variantes em todas as comunidades pesquisadas. Observa-se que do total de 1.239 amostras analisadas, a presença do traço falciforme AS foi de 5,4\% delas enquanto que as doenças falciformes SS e SC apresentaram um índice de
Tabela 1. Hemoglobinas variantes em comunidades quilombolas.

\begin{tabular}{lrc}
\hline Hemoglobinas & Frequência & Percentual \\
\hline AS & 67 & 5,4 \\
SS & 6 & 0,5 \\
AA & 1152 & 93,0 \\
AD & 7 & 0,6 \\
DD & 1 & 0,1 \\
SC & 4 & 0,3 \\
AC & 2 & 0,2 \\
Total & 1239 & 100,0 \\
\hline
\end{tabular}

acumulado de $0,8 \%$, e ainda foram evidenciadas hemoglobinas variantes $\mathrm{AC}(0,2 \%), \mathrm{AD}(0,6 \%)$ e DD $(0,1 \%)$.

Ao ser avaliada a frequência de hemoglobinas variantes por comunidades, observando as cidades sedes, o $\mathrm{N}$ amostral, o número de habitantes pesquisados por comunidades e as variações médias na presença de hemoglobinas variantes ( $\mathrm{Ta}$ bela 2), observou-se que os índices situaram-se de 0 a $21,6 \%$, sendo a comunidade quilombola Contente aquela com o maior índice de traço falciforme AS $(19,6 \%)$, bem como da anemia falciforme SS (2,0\%).

A Tabela 3 apresenta os índices de etnia, sexo e consanguinidade em comunidades quilombolas no estado do Piauí. Dos sujeitos da pesquisa que se autodeclararam negros (1.069), 84 apresentaram hemoglobinas variantes. Quanto ao sexo, 34 pessoas eram do masculino e 53 do feminino. Em relação aos aspectos de consanguinidade entre os pesquisados, 13 pessoas que apresentaram hemoglobinas variantes afirmaram possuir algum parentesco, enquanto 22 afirmaram não possuí-lo.

A hemoglobina $\mathrm{S}$ na forma homozigota, causadora da anemia falciforme, apresentou um índice médio de $0,5 \%$, semelhante à prevalência em cidades brasileiras onde a doença falciforme acomete de 0,1 a $0,3 \%$ da população negra, com tendência a atingir parcela cada vez mais significativa da população devido ao alto grau de miscigenação em nosso país. Trabalho realizado com populações quilombolas do Vale do Ribeira, no estado de São Paulo, observou uma média de 7,6\% para o traço falciforme e níveis da doença falciforme de $0,34 \%$, números semelhantes aos obtidos no presente trabalho ${ }^{3,24}$.

$\mathrm{O}$ traço falciforme apresentou uma média de $5,4 \%$, semelhante a índices pesquisados em 1.397 amostras de comunidades remanescentes de quilombos da região Nordeste do Brasil com 
Tabela 2. Hemoglobinas variantes por comunidades quilombolas no estado do Piauí.

\begin{tabular}{|c|c|c|c|c|c|c|c|c|c|}
\hline \multirow{2}{*}{ Comunidade } & \multirow{2}{*}{ Cidade } & \multirow{2}{*}{$\mathbf{N}$} & \multirow{2}{*}{$\begin{array}{c}\text { No de } \\
\text { Habitantes }\end{array}$} & \multicolumn{6}{|c|}{ Hemoglobinas variantes } \\
\hline & & & & AS & SS & $\mathrm{AC}$ & SC & $\mathrm{AD}$ & DD \\
\hline Volta do Riacho & Queimada Nova & 63 & 120 & $9,5 \%$ & $1,6 \%$ & - & $3,2 \%$ & $11 \%$ & $1,6 \%$ \\
\hline Tapuio & Queimada Nova & 62 & 128 & $6,4 \%$ & $1,6 \%$ & - & - & - & - \\
\hline Sumidouro & Queimada Nova & 64 & 140 & - & - & - & $1,5 \%$ & - & - \\
\hline Contente Angical de Baixo & Paulistana & 97 & 188 & $19,6 \%$ & $2,0 \%$ & - & - & - & - \\
\hline São Martins & Paulistana & 59 & 144 & $6,8 \%$ & - & $1,7 \%$ & - & - & - \\
\hline Cana Brava & Paulistana & 36 & 164 & $2,8 \%$ & - & - & - & - & - \\
\hline Custaneira & Sta Cruz do Piauí & 83 & 150 & - & - & - & - & - & - \\
\hline Grotões & Sta Cruz do Piauí & 153 & 200 & $2,6 \%$ & $0,6 \%$ & - & - & - & - \\
\hline Carreiras & Sta Cruz do Piauí & 78 & 90 & $1,3 \%$ & - & - & - & - & - \\
\hline Mutamba & Sta Cruz do Piauí & 111 & 160 & $4,5 \%$ & $0,9 \%$ & $0,9 \%$ & $0,9 \%$ & - & - \\
\hline Atrás da Serra & Sta Cruz do Piauí & 55 & 80 & $3,6 \%$ & - & - & - & - & - \\
\hline Lagoa Grande & Sta Cruz do Piauí & 82 & 89 & $1,2 \%$ & - & - & - & - & - \\
\hline Mimbó & Sta Cruz do Piauí & 24 & 70 & $4,2 \%$ & - & - & - & - & - \\
\hline \multirow[t]{2}{*}{ Caldeirão } & Amarante & 204 & 520 & $7,3 \%$ & - & - & - & - & - \\
\hline & Amarante & 68 & 80 & $4,6 \%$ & - & - & - & - & - \\
\hline
\end{tabular}

$\mathrm{N}$ amostral $=1.239$.

Tabela 3. Hemoglobinas variantes, etnia, sexo e consanguinidade em comunidades quilombolas do estado do Piauí.

\begin{tabular}{lrrrrrrr}
\hline & \multicolumn{3}{c}{ Etnia } & \multicolumn{2}{c}{ Sexo } & \multicolumn{2}{c}{ Consanguinidade } \\
\cline { 2 - 8 } & Hegra & Branca & Indígena & Masc & Fem & Sim & Não \\
\hline AA & 985 & 141 & 2 & 518 & 624 & 200 & 410 \\
AS & 65 & 2 & 0 & 23 & 44 & 12 & 16 \\
AC & 1 & 1 & 0 & 0 & 2 & 0 & 2 \\
AD & 7 & 0 & 0 & 5 & 2 & 4 & 1 \\
SS & 6 & 0 & 0 & 2 & 4 & 0 & 1 \\
DD & 1 & 0 & 0 & 1 & 0 & 1 & 0 \\
SC & 4 & 0 & 0 & 3 & 1 & 0 & 2 \\
Total & 1069 & 144 & 2 & 552 & 677 & 217 & 432 \\
\hline
\end{tabular}

$\chi^{2}:(\mathrm{p}<0,001 ; \mathrm{IC}=95 \%) \mathrm{Hb}$ variantes e sexo; $\chi^{2}:(\mathrm{p}<0,002 ; \mathrm{IC}=95 \%)$ Hb variantes e casamento consanguíneo; $\chi^{2}:(\mathrm{p}<0,001 ; \mathrm{IC}$ $=95 \%) \mathrm{Hb}$ variantes e etnia negra.

valores de 4,1\%. Dados apontam para uma variação média de $2 \%$ da prevalência de portadores do traço falciforme em cidades brasileiras, podendo aumentar de acordo com a região e a etnia da população analisada. Os elos ancestrais destas comunidades remanescentes de escravos com o continente africano justificam os índices maiores que a média nacional, já que na África Equatorial até $40 \%$ da população é portadora do gene da HbS em heterozigose. A Organização Mundial da Saúde estima haver aproximadamente 270 milhões de pessoas com hemoglobinas variantes. Foi observada diferença significativa $\left(X^{2}: p<\right.$ $0,001$; IC $=95 \%)$ entre as hemoglobinas variantes e a raça negra ${ }^{3,10,25}$.
Ao analisarmos as populações do ponto de vista individual, observamos que os níveis de 21,6\% de alelos da Hb S encontrados na comunidade Contente $(19,6 \%$ do traço falciforme e $2,0 \%$ da doença falciforme) em uma amostra de 97 pessoas, numa população total de 188, corroboram com os 13\% de alelos encontrados em 69 pessoas na comunidade quilombola Riacho de Sacutiaba no estado da Bahia, além dos 14,9\% encontradas na comunidade Abobral Margem Esquerda no Vale do Ribeira, onde foram pesquisadas 155 amostras numa população de 397 pessoas. No estado de Tocantins foram evidenciados índices de 6,6\% de hemoglobinas variantes $\mathrm{S}$ e C nas comunidades Malhadinha, córrego 
Fundo, Curralinho do Pontal e Manoel João, ao serem analisadas 167 amostras e 7,8\% nas comunidades Barra do Aroeira, Mata Grande e Distrito de São João, onde foi avaliado um total de 219 $\operatorname{amostras}^{24-27}$.

A elevada prevalência de hemoglobinas variantes encontradas no município de Queimada Nova e Paulistana, fronteiriças com o estado de Pernambuco e Bahia, respectivamente, além do município de Amarante, fronteira com o estado do Maranhão, corrobora as afirmações de que o estado do Piauí, no início do século XIX, teve sua ocupação influenciada por migrações vindas de Pernambuco, Bahia, Ceará, Maranhão e, em certos momentos, de Goiás e São Paulo. Neste período, os escravos eram trazidos da Bahia, São Luís e Recife ${ }^{28}$.

Em trabalho realizado com populações quilombolas do Nordeste brasileiro, a comunidade Mimbó, no estado do Piauí, apresentou uma prevalência média de $3,2 \%$ dos alelos da $\mathrm{HbS}$ em 62 amostras analisadas de um universo total de 520 habitantes. A presente pesquisa ampliou o $\mathrm{N}$ amostral, desta mesma comunidade, para 204, observando uma prevalência de 7,3\%. Ainda na mesma região fronteiriça com o estado do Maranhão, a comunidade Caldeirão apresentou um índice de 4,6\% em 68 amostras analisadas numa população de 80 habitantes $^{24}$.

Estudos afirmam que a frequência da hemoglobina S (HbS) pode variar consideravelmente na mesma região geográfica e até no mesmo estado. Nas comunidades de São Gonçalo e Riacho de Sacutiaba, ambas na Bahia, por exemplo, a freqüência desse alelo é de $0,9 \%$ e $13 \%$, respectivamente. Esses dados refletem o fato de que essas comunidades, embora compartilhem a ancestralidade africana, diferem em suas histórias de fundação e miscigenação ao longo do tempo. Em conseqüência, a prevalência da forma HbS nessas populações também é bastante diversa ${ }^{25}$.

A heterogenidade da prevalência das hemoglobinas variantes é fato observado na presente pesquisa, na qual as comunidades apresentaram um perfil diferenciado entre si para cada variação de hemoglobinas. A comunidade Cana Brava não teve hemoglobinas variantes, enquanto a Contente apresentou 21,6\%. A comunidade Volta do Riacho apresentou as variantes $\mathrm{Hb} \mathrm{DD}$ e $\mathrm{Hb}$ $\mathrm{AD}$, ainda não mencionadas em comunidades afrodescendentes rurais brasileiras.

Resultados relativos à frequência da doença falciforme em indivíduos que habitam remanescentes de quilombos permitiu concluir que a distribuição da Hemoglobina S (HbS) no Brasil é altamente heterogênea, provavelmente devido a diferenças na sua história de fundação e miscigenação, apresentando diferenças significativas mesmo entre comunidades formadas por afrodescendentes, conforme foi evidenciado nas comunidades quilombolas pesquisadas no estado do Piauí 25 .

Foi observada diferença estatisticamente significativa ( $p<0,001$; IC 95\%) entre a prevalência de hemoglobinas variantes e a raça negra (Tabela 2), demonstrando a elevada prevalência nestas amostras de comunidades remanescentes de escravos. Esta herança no Brasil trata-se de uma característica genética levando-se em conta a grande miscigenação e a significativa presença da população afro-descendente. Na Bahia, berço da colonização africana no Brasil, as hemoglobinas variantes apresentaram uma frequência de $6,9 \%$ a $15,4 \%$ em indivíduos afro-descendentes pesquisados na cidade de Salvador, caracterizando a herança genética advinda das várias regiões da África, quando do advento da escravatura ${ }^{11,29}$.

No aspecto da educação em saúde concernente à doença falciforme e ao traço falciforme, a comunidade apresentou um elevado índice de desinformação, em que $81,0 \%$ corroboraram pesquisa realiza na comunidade quilombola de Patioba, no estado de Sergipe, onde 72,3\% dos entrevistados desconheciam sobre o traço e a DF e $94,8 \%$ não sabiam a sua forma de transmissão. No estado da Bahia foi detectado que $88,9 \%$ de uma população quilombola também não possuíam conhecimentos sobre o tema. Em estudo familiar para o gene da HbS no estado de Pernambuco, $81,0 \%$ da população estudada desconheciam a doença falciforme, revelando que qualquer intervenção relativa à triagem e orientação genética de uma população deve ser seguida de informação e debate dentro da própria comunidade, já que a informação sobre a doença falciforme leva o sujeito a identificá-la e a buscar mais informação e atendimento especializado, enquanto que a desinformação leva à sua estigmatização ${ }^{30-33}$.

Quando o tema foi o local de acesso à informação sobre a anemia falciforme, apenas $23 \%$ dos pesquisados responderam afirmativamente, deste total, $26,9 \%$ a obtiveram via assembleias comunitárias, enquanto a escola apresentou um índice de $24,4 \%$, demonstrando o baixo nível de informação quando comparados à pesquisa realizada na comunidade de Caiana dos Crioulos, estado da Paraíba, onde foi observado que mais de $60 \%$ das pessoas $-22,09 \%$ mulheres e $16,13 \%$ dos homens - que responderam questionário es- 
truturado afirmaram que já tinham ouvido falar desse mal, porém quase $98 \%$ desconheciam a sua forma de transmissão, demonstrando ser a informação um desafio na construção do conhecimento sobre o tema e a educação em saúde uma ferramenta neste processo ${ }^{34}$.

No caso da anemia falciforme há um apelo no sentido de chamar as pessoas a identificarem a doença e a buscarem atendimento especializado, mas há também a ênfase na ideia de que aquelas informadas podem contribuir para prevenir seu avanço. Mediar essa tênue fronteira entre prevenção e reconhecimento das liberdades individuais pode ser considerado um desafio não só para a saúde pública, mas também para os meios de comunicação $0^{33}$.

\section{Conclusão}

O estado do Piauí, berço dos primeiros indícios de vida nas Américas, apresenta-se, segundo o censo IBGE 2000, como o quarto estado com população negra autodeclarada, dispondo de poucos indicadores relativos à herança genética da hemoglobina S. Mostramos neste estudo as hemoglobinas variantes em 15 comunidades remanescentes de quilombos no estado do Piauí, contribuindo para a educação em saúde dos membros destas comunidades frente aos aspectos da herança genética das hemoglobinas, proporcionando um passo importante na desmistificação do traço falciforme e na compreensão do que seja a doença falciforme, relevante questão de saúde pública, proporcionando subsídios para a implantação do Programa Estadual da Doença Falciforme no estado do Piauí.

A presença do poder público se faz sentir em várias ações de saúde, porém a integração destas, por meio dos projetos desenvolvidos, é importante para a consolidação do modelo de saúde publica integrado vigente no Brasil, denominado sistema único de saúde (SUS), o qual leva em conta o respeito à cultura e à autonomia do povo quilombola nas suas decisões.

A pesquisa detectou muito além de uma herança genética atribuída à doença falciforme; foram observadas as dificuldades enfrentadas no dia a dia para a conquista da cidadania plena; porém um povo altivo e guerreiro que se organiza a cada dia, resistindo e preservando as suas tradições e em busca da sua autonomia.

\section{Colaboradores}

LF Soares e MS Gonçalves participaram da concepção e do delineamento, além da escrita e tabulação dos dados; EM Lima da análise e interpretação dos dados; RMCL Verde da aprovação da versão a ser publicada; KMC Silva, SS Fernandes e SP Lins da revisão da literatura, aprovação da versão a ser publicada. JA Silva e BPGL Damasceno participaram da aprovação da versão a ser publicada, e da análise e interpretação dos dados.

\section{Agradecimentos}

Ministério da Saúde, Secretária da Saúde do Estado do Piauí, Centro de Pesquisa Gonçalo Muniz (Fiocruz-Bahia). 


\section{Referências}

1. Brasil. Ministério da Saúde (MS). Seminário Nacional de Saúde da População Negra. Brasília: MS; 2004.

2. Oliveira MF. Saúde da população negra: Brasil ano 2001 Brasília: Organização Pan-Americana da Saúde; 2003.

3. Di Nuzzo DVP, Fonseca SF. Anemia falciforme e infecções. Jornal de Pediatria 2004; 80(5):120-126.

4. Laguardia J. No fio da navalha: anemia falciforme, raça e as implicações no cuidado à saúde. Rev. Estudos Feministas 2006; 14(1):246-261.

5. Cançado RD, Jesus JA. A doença falciforme no Brasil Sickle cell disease in Brazil. Rev. Bras.Hematol. Hemoter. 2007; 29(3):203-204.

6. Steinberg MH. Sickle cell anemia, the first molecular disease: overview of molecular etiology, pathophysiology, and therapeutic approaches. The scientific World Journal 2008; 8:(1):1295-1324.

7. Paiva e Silva RB, Ramalho AS, Cassorla RMS. A anemia falciforme como problema de Saúde Pública no Brasil. Rev Saude Publica 1993; 27(1):54-58.

8. Lobo C, Marra V, Rugan MA. Consenso Brasileiro sobre atividades esportivas e militares e herança falciforme no Brasil 2007. Rev. Bras.Hematol. Hemoter 2008; 30(6):488495.

9. Galiza Neto GC, Pitombeira MS, Vieira HF, Vieira MLC, Farias DAB. Analysis of betaS-globin gene haplotypes in Ceará, Brazil. J. Bras. Patol. Med. Lab 2005; 41:315-321.

10. Naoum P. Prevalência e controle da hemoglobina $S$. Rev Brasileira de Hematologia e Hemoterapia 2000; 22(2):142-148.

11. Zago M. Considerações gerais. In: MacDowell B, organizadora. Manual de diagnóstico e tratamento de doenças falciformes. Brasília: Agência Nacional de Vigilância Sanitária; 2002. p. 7-11.

12. Oliveira NS, Silva Neto OR, Pereira MM, Oliveira SKM, Sá MAB, Ribeiro FPC, Jesus VF, Camargo CL. Anemia falciforme: informações científicas sobre uma doença que aflige a população negra e quilombola no Brasil. EFDeportes Rev. Digital. 2013; 18(183):122-125.

13. Organizações da Nações Unidas (ONU). Programa das Nações Unidas para o Desenvolvimento (PNUD) [internet]. [acessado 2013 Nov 05]. Disponível em: www. pnud.org.br

14. Munanga K. Origem e histórico do quilombo na África. Revista USP 1996; 28(5):6-63.

15. Vilas PC. A voz dos quilombos: na senda das vocalidades afro-brasileiras. Horiz. antropol. 2005; 11(24):102108.

16. CABP Santos. Quilombo Tapuio (PI): Terra de memória e identidade [dissertação]. Brasília: UnB; 2006.

17. Brasil. Ministério da Saúde (MS). A saúde da população negra e o SUS: ações afirmativas para avançar na eqüidade. Brasília: Editora do Ministério da Saúde; 2005.

18. Vieira ABD, Monteiro PS. Comunidade quilombola: análise do problema persistente do acesso à saúde, sob o enfoque da Bioética de Intervenção. Saúde em Debate 2013; 37(99):610-618.

19. Chasin ACM. Direitos étnicos, conflitos fundiários: judicialização da disputa pelos territórios quilombolas. Rev. Olhares Sociais 2012; (1):39-60.

20. Brasil. Instituto Brasileiro de Geografia e Estatística (IBGE). Dados preliminares do censo 2010. [internet]. [acessado 2012 Dez 5]. Disponível em: http://www. ibge.gov.br
21. Companhia de Desenvolvimento dos Vales do São Francisco e do Parnaíba (CODEVASF). CODEVASF Plano de Ação para o Desenvolvimento Integrado da Bacia do Parnaíba, PLANAP: síntese executiva: Território Vale do Rio Guaribas, Companhia de Desenvolvimento dos Vales do São Francisco e do Parnaíba. Brasília: CODEVASF; 2006.

22. StataCorp. Stata statistical software: release 9. College Station: Stata Corporation; 2004.

23. Chinelato-Fernandes AR, Domingos CRB. Metodologias laboratoriais para o diagnóstico de hemoglobinas variantes. Rev. Bras. Hematol. Hemoter 2006; 28(1):6570.

24. Auricchio MTBM, Vicente JP, Meyer D, Migronni-Netto C. Frequency and origins of hemoglobin S mutation in African-derived brazilian populations. Human Bio$\log y$ 2007; 79(6):667-677.

25. Pedrosa MAF, Ferreira LB, Oliveira SF. Anemia falciforme em antigos quilombos. Rev. Ciência Hoje 2004; 35(211):84-85.

26. Souza LO, Teles AF, Oliveira RJ, Lopes MAO, Souza IA, Inácio VSS, Seibert CS. Triagem das hemoglobinas S e C e a influência das condições sociais na sua distribuição: um estudo em quatro comunidades quilombolas do Estado do Tocantins. Saude soc 2015; 22(4):1236-1246.

27. Andrade SP, Teles AF, Souza LO, Silva LC, Oliveira RJ, Santos MG, Seibert CS. A distribuição da hemoglobina $\mathrm{S}$ em três comunidades quilombolas do estado do Tocantins-Brasil. Scientia Amazonia 2015; 4(1):10-20.

28. Marcondes RL, Falci MBK. Escravidão e reprodução no Piauí: Oeiras e Teresina (1875). Ribeirão Preto: Universidade de São Paulo; 2001. (Texto para Dicussão-Série Economia)

29. Gonçalves MS, Bonfim GC, Maciel E, Cerqueira I, Lyra I, Zanette A, Bomfim G, Adorno EV, Albuquerque AL, Pontes A, Dupuit MF, Fernandes GB, Reis MG. S haplotypes in sickle cell anemia patients from Salvador, Bahia, Northearstern Brazil. Braz. J. Med. Biol. Res. 2003; 36(10):1283-1288.

30. Meneses RCT, Zeni PF, Oliveira CCC, Melo CM. Promoção de saúde em população quilombola nordestina - análise de intervenção educativa em anemia falciforme. Esc Anna Nery 2015; 19(1):132-139.

31. Magalhães LS, Neves, TA, Coswosk ED. Nível de conhecimento da população de Helvécia/BA sobre anemia falciforme e a prevalência da hemoglobina $\mathrm{S}$ em indivíduos de 7 a 14 anos: uma correlação. Resumos do $54^{\circ}$ Congresso Brasileiro de Genética; 2008 Set 16-19; Bahia, Salvador; 2008.

32. Bandeira FMGC. Triagem familiar para o gene $\mathrm{HBB}^{\star} \mathrm{S}$ e detecção de novos casos de traço falciforme em Pernambuco. Rev Saude Publica 2008; 42(2):2-7.

33. Diniz D, Guedes C. Informação genética na mídia impressa: a anemia falciforme em questão. Cien Saude Colet 2006; 11(4):1055-1062.

34. Novaes da Silva JA. Condições Sanitárias e de Saúde em Caiana dos Crioulos, uma Comunidade Quilombola do Estado da Paraíba. Saúde Soc 2007; 16(2):111-124.

Artigo apresentado em 08/12/2015

Aprovado em 23/03/2016

Versão final apresentada em 25/03/2016 